\title{
Public Health Foundation, Bangladesh: Programs and Activities - 2004
}

Public Health Foundation of Bangladesh is an independent, autonomous, non-political and non-profitable organization and led by a group of well reputed, committed \& dedicated physicians, researchers, clinicians, public health specialists and other multidisciplinary health professionals from home and abroad. It aims to make a positive desirable change by establishing a fairer, more equitable and healthier society with the objectives of addressing priority public health challenges with activities, mobilizing resources, and delivering health services.

\section{Awareness program on Hand Washing at a Primary School}

'Public Health Foundation of Bangladesh (phfbd)' organized an awareness program on 'Hand washing' at 'Asroy', a Primary School for street children in Hazaribag, Dhaka on 27 January 2014, with the theme 'Hand Wash in Safeguarding Health'. Students were taught the 7 steps of hand washing as per WHO guidelines. Subsequent monitoring of this hand wash practice was done by the school teachers and they reported to the concerned authority of phfbd that the students were maintaining this practice with full enthusiasm at school and at home.

\section{Training on First Aid at a Garment Factory}

A day long First Aid training program was successfully conducted by phfbd on 12 February, 2014 at the Young Socks Ltd. factory in Ashulia, Savar. A total of 30 workers participated in the training program.

\section{Workshop on Stress Management and Joyful Living}

Three workshops on 'Stress Management and Joyful Living' was organized by phfbd on 24, 25 \& 26 April, 2014. A total of 90 participants from various organizations successfully conducted the sessions. The resource person was Prof. Rajeev Saxena, Head of General Pathology, Sinhgad Dental College and Hospital, Pune, India.

\section{Health camp for Autistic Children}

In collaboration with the Autism Welfare Foundation (AWF), phfbd organized a Health Camp on 10 April, 2014 at 'Kanon (AWF)' school for autistic children at Mohammadpur, Dhaka, to render pediatric and eye health care. About 160 autistic children were examined and parents were duly advised about the treatment and prevention of the ailments of their children.

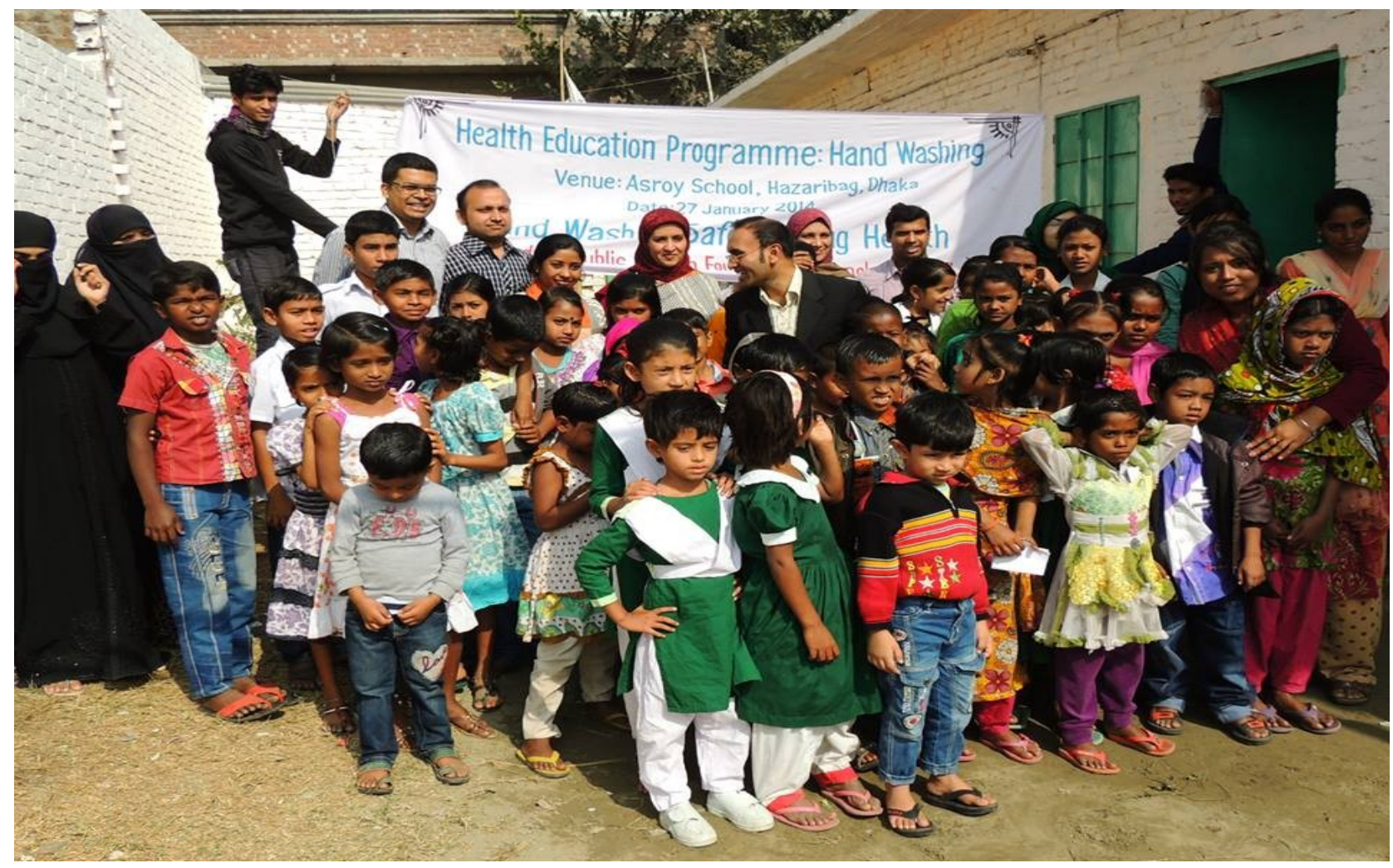

South East Asia Journal of Public Health 2014;4(2):60-62. C 2014 publisher and licensee Public Health Foundation Bangladesh. 


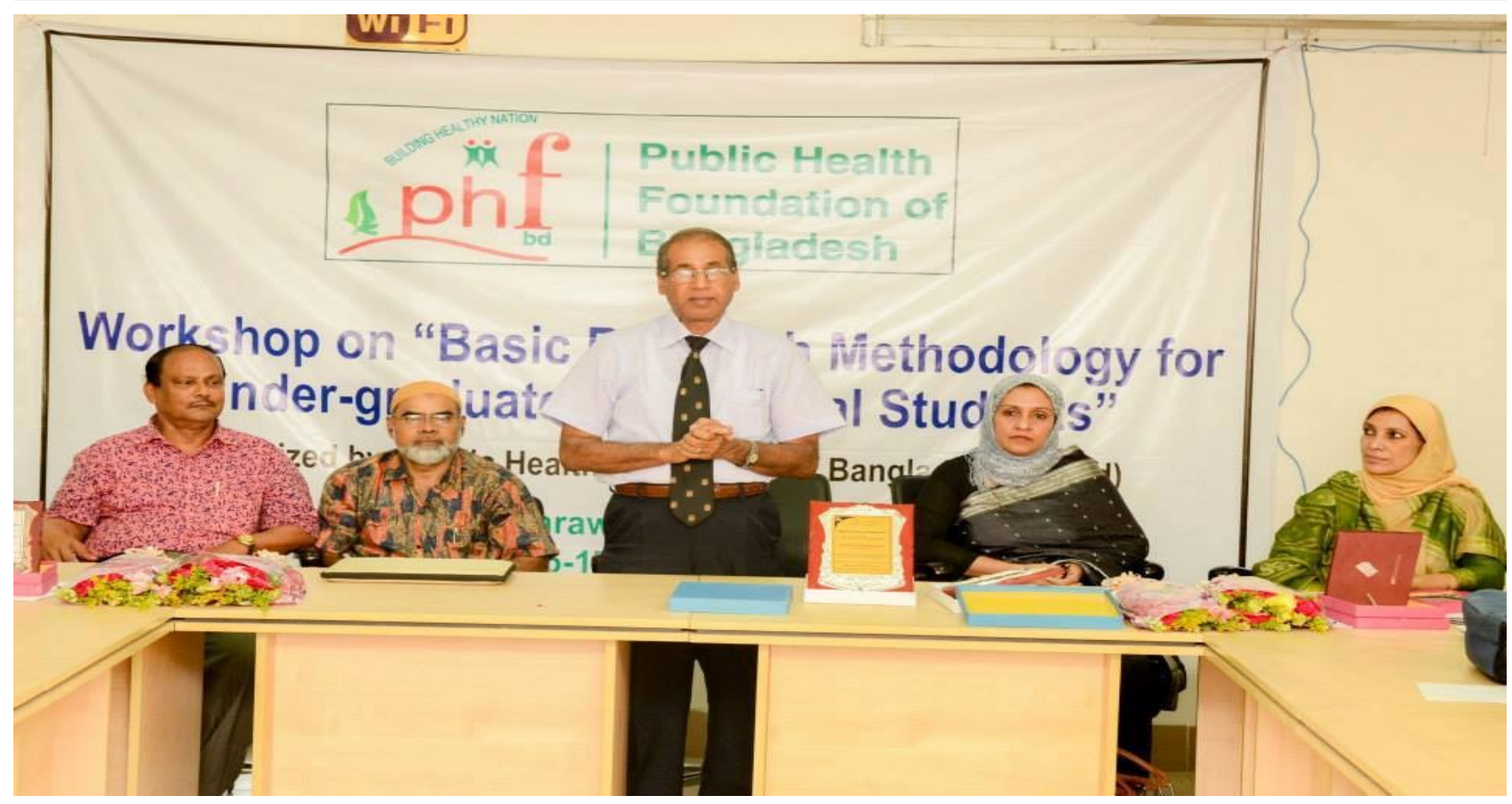

Training on Basic and Applied Research Methodology

Four days of training on 'Basic and Applied Research Methodology' was organized by phfbd from 18-21 May, 2014 at Shaheed Suhrawardy Medical College. Participants were the undergraduate and post graduate students of health science of various institutions.

\section{Seminar on Food Safety}

In collaboration with RDRS, phfbd organized an interactive seminar on "Food Safety" on 15 July, 2014 at the Senate Bhaban of Dhaka University. The keynote speaker was Prof. Dr. Muzaherul Huq, Chairman, phfbd.

\section{Aynus International Conference}

Along with the Ayurved and Naturopathy Association of Bangladesh, Phfbd was the coorganizer of the $3^{\text {rd }}$ Aynus International Ayurvedic and Traditional Medicine Conference, on 29 November, 2014 at Senate Bhaban, Dhaka University, Dhaka.

\section{Public Health Foundation Day}

The $2^{\text {nd }}$ Public Health Foundation day was celebrated by phfbd on December 8, 2014. On this occasion a 2 day long scientific conference was organized at Sasakawa Auditorium, icddr,b, Mohakhali, Dhaka on 7-8 December, 2014.

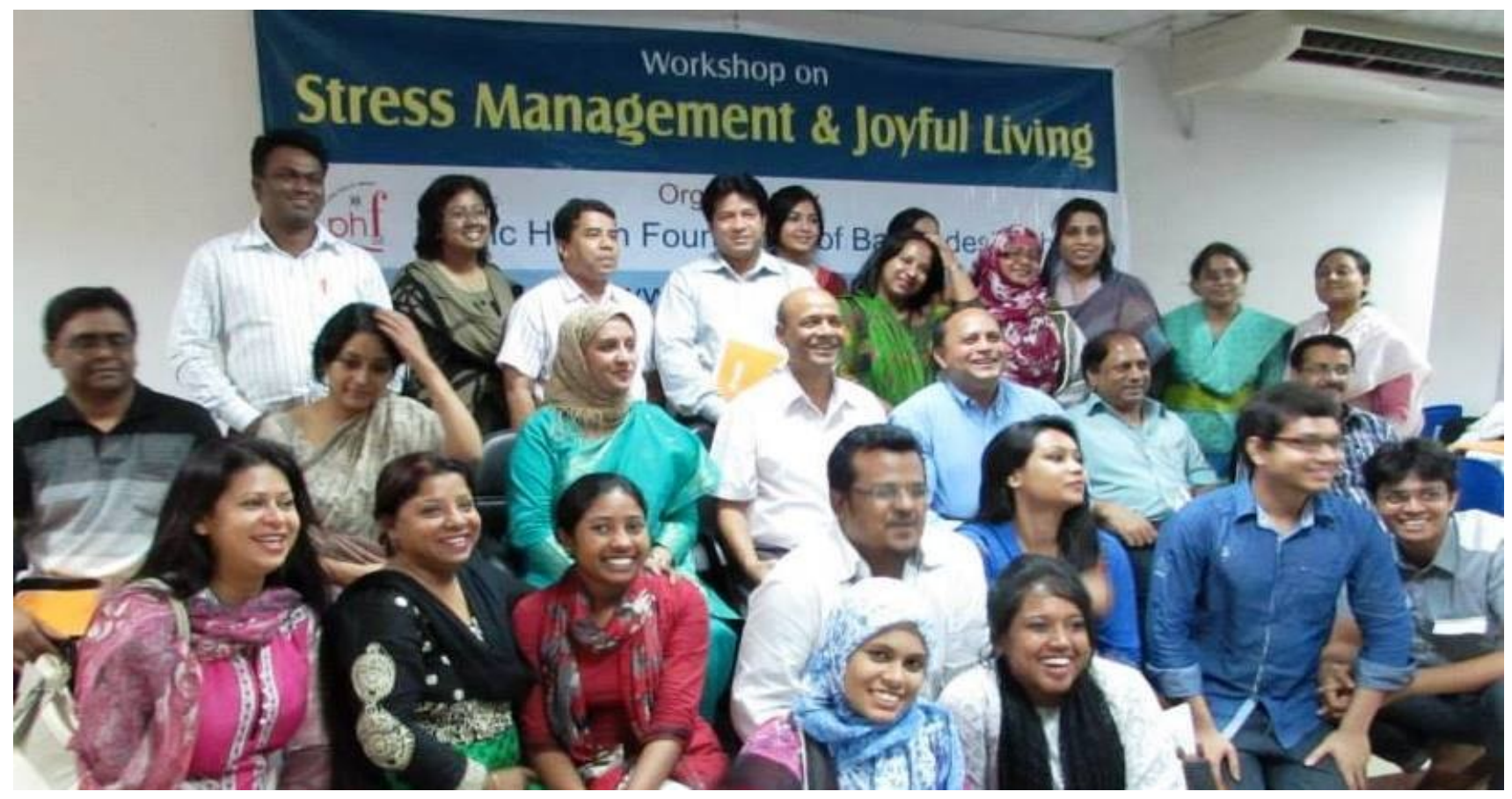


Prof. Dr. Mahmud Hasan, President, Bangladesh Medical Association (BMA) was the honorable Chief Guest in the inaugural session, while Prof. Dr. Akhtarun Naher, Director, NIPSOM and Dr. Moazzem Hossain, President, Bangladesh Private Medical College Association (BPMCA) and Dr. John D Clemens, Executive Director, icddr,b were the Special Guests. Prof. Dr. Muzaherul Huq, Chairman of the foundation, presided over the inaugural session.

The whole program was coordinated by Prof. Dr. Sharmeen Yasmeen, Chief Executive Officer (CEO) of phfbd. Dr. Aftabuddin of icddr,b worked as the Local Coordinator. Medical students of Bangladesh Medical College, Shaheed Suhrawardy Medical College, Faridpur Medical College, and NITOR worked as Public Health Volunteers.

Public health awards were distributed to two eminent personalities who have contributed to public health education and public health service. Professor Dr. M Q K Talukder, Chairman, CWCH was awarded for promoting public health education and Mr. Shykh Seraj, Founder Director, Impress Telefilm Ltd and Head of News, Channel i was awarded for promoting the public health service in Bangladesh.

The main objective of the conference was to encourage public health professionals and researchers to share the platform with other health professionals who are also the involved in promoting public health in Bangladesh. The conference participants had the scope to share their innovative thoughts and ideas with others towards building a healthy nation with a public health approach to our health system.

In the two days of scientific sessions, public health professionals from home and abroad presented their scientific and research papers in scientific sessions based on 10 public health themes. All the sessions were chaired by eminent professionals and academics of Bangladesh.

Prof. T.A. Chowdhury, Prof. Dr. A. M. Zakir Hussain and Prof. Badrul H Khan presented keynote papers.

Various NGOs in the field of public health were also given the opportunity to disseminate their activities and best learning experiences. Furthermore, a good number of posters were also exhibited by some younger health professionals.

The program was ended with the announcement of the invitation to the ' 3 nd Public Health Foundation Day' to be observed on December 08, 2015.
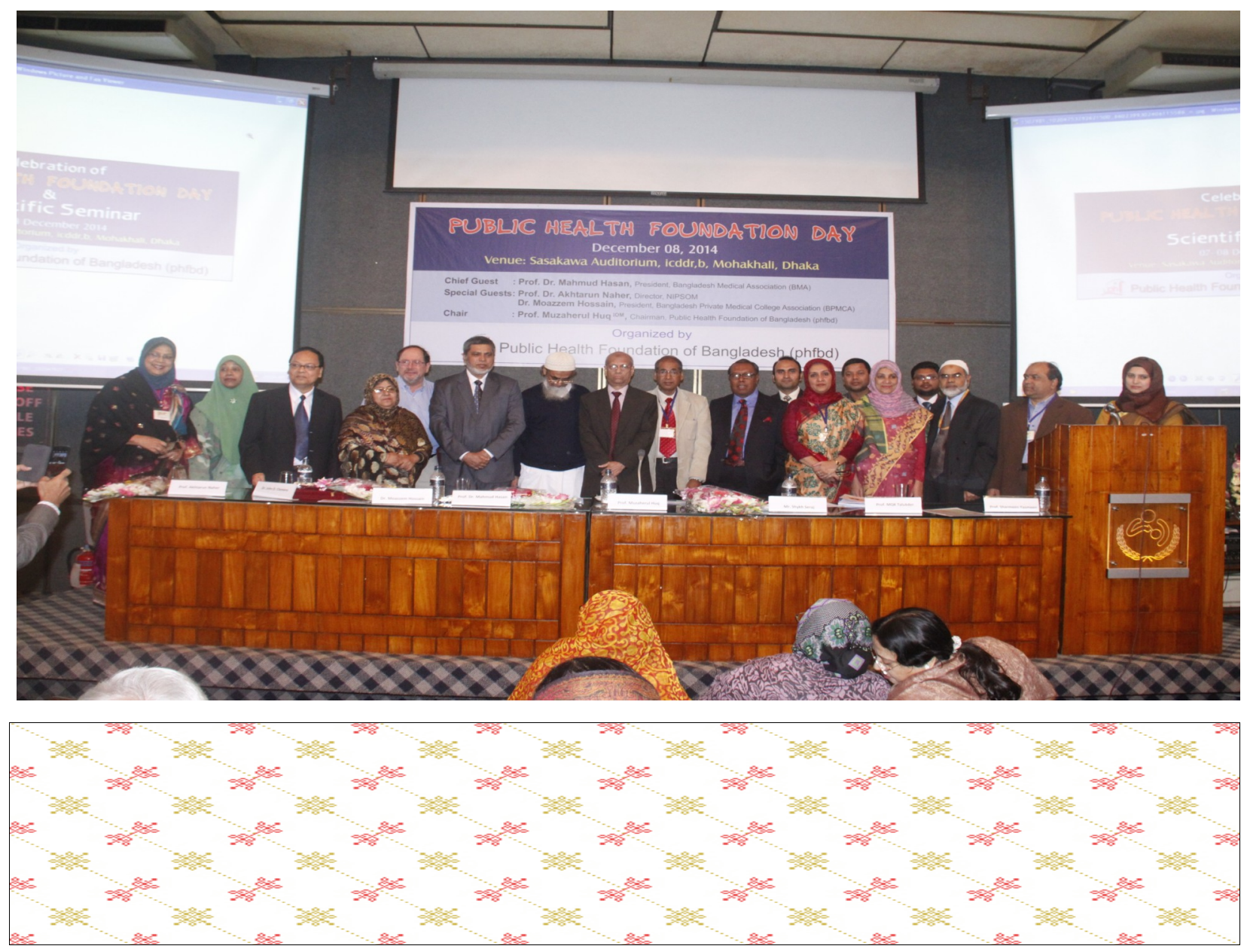